\title{
Fordism and Positivism in U.S. Sociology
}

\author{
Val Burris
}

A specter is haunting the human sciences-the specter of positivism.

“Despite repeated attempts by social theorists and researchers to drive a stake through the heart of the vampire," George Steinmetz (2005a: 3) writes in his introduction to The Politics of Method in the Human Sciences, "the disciplines continue to experience a positivistic haunting." To be sure, the positivism of which Steinmetz writes is not the assertive, self-identified positivism of August Comte, Emile Durkheim, or the Vienna Circle-or even the more circumspect, but still recognizable, positivism of the likes of Karl Popper. Rather, we are confronted here with a more elusive phantom-one that appears primarily in "latent, unexamined, and unconscious forms" (Steinmetz (2005a: 3). According to Steinmetz, this positivistic demon advances and retreats unevenly within and across the human science disciplines, discards one costume for another to elude detection, but resists all efforts to exorcise it, once and for all, from the practice of social and historical research. Detecting the comings and goings of this phantom and conjuring possibilities for its ultimate and overdue demise provide the overarching goals and organizing framework around which Steinmetz seeks to impose a semblance of order on this otherwise eclectic collection of essays on methodological debates and developments in the human sciences.

The results of Steinmetz's editorial efforts are in many ways impressive. The individual essays are informed, insightful, and often provocative. For readers like myself, whose expertise and familiarity with 
questions of method are limited mainly to a single discipline, the volume offers a window on methodological practices and trends in neighboring disciplines that often confounds, or at least complicates, widely held stereotypes. The juxtaposition of multiple disciplines provides the reader with a comparative perspective on positivism's influence in the human sciences that is more systematic and encompassing than anything previously attempted. And for those who have not followed recent developments in the philosophy of social science, the volume provides a refresher course in these topics that is thankfully free of jargon and highly relevant to the concrete decisions one confronts in the practice of social research.

My comments primarily focus on Steinmetz's own contribution to the volume-an ambitious and stimulating essay on the social foundations of positivism in postwar U.S. sociology. But before I turn to that topic, it is worth touching on other highlights of the collection. The volume is divided into two parts. Part 1 presents historical overviews of half a dozen human science disciplines, with a focus on the positivist and nonpositivist currents that shaped their twentieth-century development. Part 2 is addressed more to the future and to the emerging alternatives to positivism in many of these same disciplines. Nevertheless, there is considerable overlap in the issues addressed by the essays in parts 1 and 2 .

The impressions that result from this cross-disciplinary survey of the human sciences are sometimes consonant with what I take to be the conventional wisdom, but frequently not. On the one hand, there is near 
consensus among the contributors to the volume that U.S. sociology moved decisively in the direction of positivism in the postwar decades but that the hegemony of positivistic methods has become more widely contested in recent years. Whatever disagreements may exist regarding the precise meaning of the label positivism, the reasons for its postwar ascendance, and judgments about its benefits and liabilities, I suspect that most sociologists would not dispute this general description of their field. On the other hand, I also suspect that many readers, like me, would be inclined to see economics, with its atomizing ontology, its penchant for quantification, and its quest for lawlike generalizations, as the most consistently positivistic of the human sciences. While some contributors to the volume concur in this opinion, most of those writing from within the economics discipline tell a more complicated story of the development and diversity of methodological viewpoints in their field.

Like sociology, political science is depicted as falling under the shadow of positivism in the postwar period-initially with the rise of behaviorism and then with the ascendance of rational choice theory. But in a more pronounced sense than sociology, political science retains a vital and relatively autonomous subfield devoted to theory, which frequently has taken an oppositional stance to positivism. The strongest resistance to positivism is revealed by cultural anthropology-a discipline that, since Franz Boas, has shunned generalization and emphasized the incomparable uniqueness of cultures and the necessity of reflexivity in the interpretation of one culture from the standpoint of another. History has also been relatively immune to 
positivism, with the exception of a brief interlude associated with the rise of social history in the 1960s and 1970s-a trend that was soon eclipsed by the culturalist turn of the discipline in the 1980s.

I would give a false impression of the book, however, if I were to speak only of the broad panorama that it provides on the comparative history of method and research practice in the human science disciplines. As valuable as this may be, many of the most stimulating essays in the collection address much narrower topics. For example, Margaret Somers delivers a penetrating critique of sociology's current fixation with "social capital" and a recounting of how a concept that originated as a way of addressing the social embeddedness of markets has been largely subsumed within a rational choice framework that is antithetical to any genuinely relational concept of the social. Writing in an autobiographical mode, William $H$. Sewell J r. reflects on the dilemmas he encountered in seeking to navigate the shifting tides of political and academic fashion that swept through the history profession from the 1960s through the 1990s. Philip Mirowski offers a meticulously detailed and uncompromising argument for the pivotal significance of academic involvement in military operations research during World War II in forging a new relation between science and the state and preparing the way for the ascendance of positivism in the postwar period. Sandra Harding advances the novel, if not heretical, thesis of an affinity between logical positivism and the antipositivism of standpoint epistemology by forcing us to take seriously the genuine commitment of early logical positivism to many of the same progressive political ideals that are now 
widely seen as antithetical to positivism. And in an inspired and original essay, Andrew Abbott examines the relatively restricted forms of temporality that are implicated in sociological research and the prospects for moving beyond these. Limitations of space prevent me from mentioning other equally stimulating contributions, but these should suffice to give a sense of the breadth and depth of the volume.

Having described the broad contours of the book, I now turn to Steinmetz's own contribution to the volume. Steinmetz's essay on the sociopolitical foundations of positivism in postwar U.S. sociology can be viewed as the keystone in the overall architecture of the book. Not only does it offer the most comprehensive theory of the circumstances giving rise to positivism in the human sciences, but it also provides the framework that Steinmetz uses in his introduction to situate both the supporting and the discordant themes encountered in the essays of other contributors. Because much of what I have to say is critical of Steinmetz's main thesis, it is important to state at the outset that this is a very impressive and thoughtprovoking essay. Steinmetz's writing is distinguished by its conceptual clarity and by the boldness with which he sets forth an original and far-reaching thesis with little of the hedging or waffling that saps so much academic writing. Indeed, it is partly because of Steinmetz's lucidity and his willingness to follow through on the logic of his argument that his essay invites criticism and encourages dialogue.

The opening section of Steinmetz's (2005b) essay offers us a working definition of what he calls "methodological positivism"- his term for the type 
of positivism that he believes is hegemonic in sociology. Methodological positivism, he says, is distinguished from other, past or present, variants of positivism by its adherence to three core principles. The first is an empiricist ontology, by which he means the assertion that only observables are real and therefore appropriate as objects of scientific knowledge. This implies a proscription of knowledge statements referring to unobservable entities or mechanisms as anything more than a shorthand for accounts that could, if necessary, be translated into equivalent statements about observables. The second is a positivist epistemology as articulated by the logical positivists and their successors, by which he means the assertion that scientific explanations take the form of covering laws of the type "if A then B." This implies that social reality is constructed as a closed system rather than as an open one, as this is the only situation that would allow such constant conjunctions to be universally valid. The third is scientism, by which he means a belief in the unity of the natural and the social sciences. Included under this principle are such methodological precepts as a preference for quantification, a strict division between facts and values, and a belief in the concept, time, and space independence of social mechanisms.

Steinmetz acknowledges that relatively few sociologists openly advocate such methodological principles. One would look in vain for a positivist manifesto signed by a list of prominent sociologists. He also acknowledges that the image that sociology presents to superficial observation is markedly different from the one captured in his concept of methodological positivism. On the surface, the discipline of sociology has the 
appearance of a methodological Tower of Babel, where social constructionism, cultural relativism, standpoint epistemology, and other nonpositivist perspectives are the voices most likely to be heard. Quantification is scorned as much as it is praised, and political value commitments are widely argued to be inseparable from the practice and results of sociological research.

Nevertheless, Steinmetz maintains that the top sociology journals and departments remain pristinely aloof from this epistemological diversity and controversy. Most simply retreat from any engagement in explicit epistemological discussion and carry on with what he describes as "cryptopositivism" (Steinmetz 2005b: 276). Moreover, from their citadels overlooking the discipline, sociological elites, through the power of their example, sustain this positivism that dare not speak its name as the hegemonic perspective of the field. The privileged position of this cryptopositivism is acknowledged as a fact of life, even by those in the discipline (perhaps a majority) who engage in other forms of sociological practice or who question its legitimacy.

My reactions to this general description of the place of positivism in U.S. sociology are mixed. I believe that Steinmetz is right to point to a disjuncture between the type of sociology that is practiced in the top journals and departments and what one encounters in the discipline at large. Whether or not this is unique to sociology, it is indeed a puzzle that deserves closer attention, and I will return to it later in my remarks. On the larger question of the hegemony of methodological positivism as defined by Steinmetz, my 
reaction is twofold. First, I think it is a mistake to lump together empiricism, positivism, and scientism as a single methodological perspective. Certainly, there is no logical sense in which any one these isms implies either of the other two (Keat 1981). Steinmetz admits that the specific combination of these methodological assumptions has varied across time, subfield, and setting and from one sociologist to the next. Nevertheless, I have a distinct sense that he is setting the table for an argument of guilt by association, whereby signs of any one of these symptoms is taken as grounds for confirming the larger malady. Or, more accurately, I think that he is setting the table for what might be called "explanation by association," wherein the thing (positivism) explained is allowed to shift among different meanings during a very complex and overdetermined explanatory story.

Second, whatever may have been the case in the early postwar period, I question whether Steinmetz's portrayal of methodological positivism accurately captures the overt or latent methodological and epistemological beliefs of contemporary sociologists whose work is shaped by the research protocols of the leading journals and departments. Admittedly, many such sociologists are relatively unreflective about such issues, but I believe that if they read Steinmetz's essay and had the choices laid out to them, they would reject the notion that the underlying mechanisms posited in their theories or explanations are any less real just because they are not directly observable. They would explain that whatever causal claims they might make of the form "if A then B" are mainly probabilistic claims of tendency and are based on data that surely exclude relevant variables and oversimplify the irreducibly 
complex interaction among causal mechanisms. Although they might affirm that generalizability is something to be sought, they would rarely argue for the universality of their findings across all times and cultures. And whether or not it caused them to question the value neutrality of their research, most would also acknowledge that their findings are to some extent framed by concepts that their theories define as salient. How one would adjudicate between these two very different assessments of the epistemological assumptions dominating the discipline is hard to imagine, especially given Steinmetz's claim that the methodological positivism of which he speaks is "unconscious" rather than conscious and "cryptic" rather than openly avowed.

These criticisms aside, I have a clear sense that the multifaceted phenomenon that Steinmetz describes under the label of methodological positivism, which he says rose to prominence in sociology from roughly 1945 to 1965 , and that he sees as more pronounced in the top journals and departments than in the discipline as a whole is something that I also recognize-however much we may disagree on what lies at the root of this phenomenon or how it manifests itself today. Of the three doctrines that Steinmetz collapses into the concept of methodological positivism, he clearly believes that the epistemological principle of explanation in terms of covering laws of the type "if A then $B$ " is the core and defining feature of the larger syndrome. For myself, I tend to see what most people describe or criticize as positivism as better captured by some of the methodological assumptions and aspirations that he discusses, somewhat pejoratively, under the label of 
scientism or what I would prefer to call naturalism. For the sake of delving deeper into Steinmetz's argument, however, let me set these differences aside and turn to the central and most original thesis of Steinmetz's essay: his explanation of the causes for the historical ascendance of positivism in U.S. sociology during the postwar era.

At the heart of Steinmetz's (2005b: 290) essay is his argument for an "externalist" or "social epochal" explanation of the dominance of positivism in sociology in the postwar period. He contrasts this with the more familiar "internalist" accounts of the shaping of sociological taste or practice, which he rejects as inadequate to explain the rise and persistence of positivism. For example, he rejects the idea that positivism is either the result of the priorities of funding agencies or an imitation of the natural sciences in the pursuit of greater prestige as insufficient to account for sociology's turn to positivism. I could not help but notice that, in establishing the necessity of an externalist account of sociological positivism, Steinmetz follows essentially the same strategy as that archpositivist Durkheim, who sought to establish the necessity of a externalist account of such seemingly internal, subjective phenomena as suicide through a process of argument by exclusion. Moreover, Steinmetz's arguments for exclusion often follow a comparative method, variants of which Durkheim embraced as the foundation of sociological positivism. For example, Steinmetz reasons that the thesis that new sciences emulate currently prestigious sciences must be rejected as an explanation of sociological positivism because it is inconsistent with the fact that anthropology did not follow a similar path. He rejects the thesis that the 
pursuit of outside funding led sociology to cloak itself in positivism because sociology also relied on outside funding in the prewar period without yielding this result. In fairness, Steinmetz is careful not to reject internalist accounts in toto but only to argue that they fall short of a complete explanation. My point here is not to take issue with Steinmetz's reasoning but merely to point out that arguments that are logically akin to the method of constant conjunction are omnipresent in sociology and their presence should not, in itself, be taken as evidence of a positivist epistemology.

The strength of Steinmetz's case for an externalist account of sociological positivism lies in his creative application and extension of what is known as "regulation theory"-an offshoot of the Marxist theory of capital accumulation that views capitalism as proceeding through a number of discrete stages, each with its own distinctive institutions, mechanisms, and discourses through which the expanded reproduction of capital as a social relation is secured (Jessop 1990; Brenner and Glick 1991). Associated with most regulation theories is the concept of "Fordism," a stage of capital accumulation that began to crystallize in the 1930s, first in the United States and then elsewhere, and that became the dominant mode of social regulation in the postwar era. Various connotations are given to Fordism, but among these Steinmetz emphasizes the following: the spread of technologies of mass production and markets for mass consumption, the stabilization of economic cycles through Keynesian fiscal policy, a class compromise between capital and labor in the core industries, the emergence of a homogenizing mass culture, suburbanization, the predominance of the male breadwinner- 
female homemaker family form, and the tendency for social practices to be contained within nation-states. Steinmetz then identifies five links between Fordism as a historical epoch and positivism as a form of sociological practice that unconsciously reproduced the historically distinctive features of Fordism in its methodological assumptions.

First, he argues that the Fordist form of governability created an enhanced role for social science and an increase in state and foundation support for research on the model of the natural sciences. On this point I am in complete agreement, although it is unclear from Steinmetz's earlier comments whether this should count as an internalist or an externalist explanation of sociological positivism. And it is unclear whether this should be understood mainly as an incentive to scientism or to the entire ensemble of ontological and epistemological principles that Steinmetz collapses under the label of methodological positivism.

Second, Steinmetz argues that the relative economic stability of the Fordist era encouraged sociologists to believe in the regularity and repeatability of social practices, adding plausibility to the quest for sociological knowledge through the pursuit of general covering laws, statistical models, replicable experiments, and reliable predictions. On this point I am more doubtful, mainly because I am not persuaded of the existence of any plausible chain of causal mechanisms that could lead from such a broad, aggregate feature of the national economy to the cognitive predispositions of sociologists in their diverse areas of study. Why should economic stability be any more conducive to a belief in the regularity of 
social phenomena than cyclical economic crises? Doesn't economic instability often lead people to search for more secure and invariant foundations of belief? And doesn't economic security often free people to experiment with alternative (exotic, relativist, or utopian) modes of thought?

Given these conflicting possibilities, it is hard for me to see Steinmetz's view of Fordism as anything but an instance of what Louis Althusser (1969) called an "expressive totality" in which the essence of the Fordist totalitythat is, the seemingly natural permanence of existing institutions-is manifested homogeneously across social consciousness in all its forms. In this respect, Steinmetz's thesis bears a striking resemblance to the earlier argument of Georg Lukács (1971 [1922]), who, decades before the consolidation of Fordism, saw the bureaucratic capitalism depicted by Max Weber and the organized, crisis-free capitalism proclaimed by Eduard Bernstein as a seamless totality in which reified habits of thought permeated every social sphere from philosophy to science to law (Stedman Jones 1971).

Third, Steinmetz argues that Fordism, through its homogenization of culture, contributed to a belief in universal, interchangeable subjectivity that lent credibility to objectivist and culture-blind perspectives like behaviorism and modernization theory and obviated any need to study subjectivity in any real depth. I think this is a more plausible thesis, but I cannot help but ask: Aren't there also profoundly nonpositivist versions of the belief in a universal, interchangeable subjectivity (e.g., G. W. F. Hegel and the entire tradition of German idealism, including the young Karl Marx) that are equally consonant with the Fordist suppression of cultural specificity? And haven't these as well 
as more positivist variants of the belief in universal human subjectivity been ascendant at many times and places long before the advent of Fordism?

Fourth, Steinmetz argues that the spatial salience of the nation-state in Fordism and the homogenization of domestic space led to a blindness to spatial and hence cultural variability among socially causal mechanisms. This thesis partly overlaps with the previous one, and, again, I find some plausibility here, but I think the homogeneity of national and domestic space in the postwar era is easily exaggerated. This was also a time in which residential segregation by race became increasingly difficult to ignore, and the rapid entry of women into the labor force yielded profound changes in domestic space. When Steinmetz (2005b: 301) notes as evidence of this thesis that identical models of social behavior were applied equally to "innercity rioters, campus antiwar protesters, and Vietnamese peasants," it is difficult to see how the plausibility of such context-independent models can be seen as having arisen organically from the homogeneity of their spatial context rather than having been forcibly imposed on their subject matter.

Fifth, Steinmetz argues that the distinctive form of postwar U.S. imperialism, which he depicts as aimed at conquering hearts and minds not just with gunships but with Coca-Cola, lent additional pressure to the development of a generalizing approach to non-Western culture. Steinmetz's advocacy of this thesis is more qualified than the earlier ones in that he also notes an imperialist countertendency toward the revival of racist forms of cultural essentialism. I find little to object to here. However, I would note that, in terms of what I take to be its underlying causal mechanisms, this 
thesis has much in common with the first, which was realized largely through the influence of state and foundation funding.

My overall assessment of Steinmetz's case for the Fordist roots of positivism in postwar U.S. sociology is that, while I find the thesis provocative and its presentation filled with many gems of insight, I am much more likely to be persuaded by causal mechanisms that are more proximate, that make more direct reference to actors' motives, especially motives framed in terms of material or status interests, and that do not rely on such sweeping assumptions about the collective mind-set of an era and its diffuse impact on sociologists as general members of society.

By way of conclusion, let me return to a question posed earlier: How do we make sense of the divergence that Steinmetz notes between at least the semblance of positivism at the level of the leading journals and departments and the pervasiveness of nonpositivist perspectives in the discipline as a whole? My own view is that this is better described in terms of variations across the discipline between those who find key aspects of the natural sciences worthy of emulation (naturalism) and those who find them unsuited to social research (antinaturalism). More specifically, I would say that the most visible and contested fault line in sociology is between those who practice mostly quantitative research and those who practice mostly qualitative research, where the former are often accused of wielding disproportionate influence in the discipline. Although quantitative methods are widely perceived as more "positivistic" than qualitative methods, a strong case can be made that both quantitative and qualitative methods are 
potentially compatible with what Steinmetz approvingly refers to as "critical realism" as an alternative to positivism (Porpora 2001; Pratschke 2003). Hence I would argue that the major methodological divide in sociology cannot be subsumed under Steinmetz's distinction between positivism and antipositivism.

Implicated in the debate over quantitative versus qualitative methods are both genuine differences about the most valued forms of sociological knowledge and competing career ambitions. If ever there were a specter haunting sociology, it is this dichotomy, which shows no sign of abating despite the many reasoned appeals for methodological pluralism (Little 1991) and despite the fact that many individual sociologists easily straddle both sides of the line. Were this only a dispute about epistemology, I believe the debate would long since have ended and been declared a draw. But insofar as the quantitative-qualitative dichotomy is intertwined with the contest for disciplinary prestige and the relative valuation of different kinds of intellectual capital, the prospects for a negotiated truce are more problematic.

If forced to make a prediction, I would judge that the current privileging of quantitative methods in sociology is a precarious state of affairs and that qualitative methods will inevitably achieve parity, or even dominance, in the top journals and departments of the field. Among other reasons, this is likely because of the positive strides that the discipline has made toward gender equity and the stronger affinity of female sociologists 
for qualitative methods (Grant et al. 1987). Some elite departments appear to have already cast their lots with the rising tide of qualitative sociology. And at least one attempt has come close to wresting control of the American Sociological Review from the more quantitatively oriented departments.

My own sympathies in this contest are mixed. While I agree that the quantitative emphasis of journals like American Sociological Review and American Journal of Sociology often favors technical competence over theoretical innovation, I also believe that the rules of evidence in quantitative sociology are more open to the acceptance of novel, unanticipated, or even controversial findings than are those in qualitative sociology, where the elusive standards of validity make it less likely that anomalous or discomforting evidence will prevail against the dominant beliefs and fashions of the field. And while I agree that most quantitative research gives insufficient attention to the cultural variability of socially causal mechanisms, I also believe that the logical protocols of quantitative sociology are more democratic in the sense of allowing entry to scholars with strong analytic skills, regardless of their class, national, or cultural origins, and that a hegemonic qualitative sociology, whose main currency is cultural capital and facility with language, would fall even more firmly under the dominance of those from privileged social and educational backgrounds. As an example of the latter, we need look no farther than history, which a recent analysis revealed to be more heavily dominated by a small handful of mainly Ivy League departments than either sociology or political science (Burris 2004). 
The best one can hope for is that sociology can achieve not just parity but a genuine rapprochement between quantitative and qualitative methods. As a start, might we not simply agree that quantitative measures and models are indispensable for evaluating the empirical adequacy of many kinds of descriptive and causal assertions about the social world, just as qualitative interpretation is indispensable for reconstructing the meanings that are implicated in many kinds of culturally and historically specific forms of social action? Such a modest consensus leaves much room for methodological diversity and disputation, but it would go a long way toward delivering the discipline from both the "ghost of positivism" and its accompanying train of vigilant ghostbusters. 


\section{References}

Althusser, Louis (1969) For Marx. New York: Vintage.

Brenner, Robert, and Mark Glick (1991) “The regulation approach:

Theory and history." New Left Review, no. 188: 45-119.

Burris, Val (2004) "The academic caste system: Prestige hierarchies in PhD exchange networks." American Sociological Review 69: 239-64.

Grant, Linda, Kathryn B. Ward, and Xue Lan Rong (1987) "Is there an association between gender and methods in sociological research?" American Sociological Review 52: 856-62.

Jessop, Bob (1990) "Regulation theories: Retrospect and prospect." Economy and Society 19: 153-216.

Keat, Russell (1981) The Politics of Social Theory. Oxford: Blackwell.

Little, Daniel (1991) Varieties of Social Explanation. Boulder, CO: Westview.

Lukács, Georg (1971 [1922]) History and Class Consciousness. London: Merlin.

Porpora, Douglas (2001) "Do realists run regressions?" in Garry Potter and J ose Lopez (eds.) After Postmodernism? Critical Realism. London: Continuum: 260-68.

Pratschke, J onathan (2003) "Realistic models? Critical realism and statistical models in the social sciences." Philosophica 71: 13-35. 
Stedman J ones, Gareth (1971) “The Marxism of the early Lukács: An evaluation." New Left Review, no. 70: 27-64.

Steinmetz, George (2005a) "Positivism and its others in the social sciences," in George Steinmetz (ed.) The Politics of Method in the Human Sciences: Positivism and Its Epistemological Others. Durham, NC: Duke University Press: 1-56.

- - (2005b) "Scientific authority and the transition to post-Fordism: The plausibility of positivism in U.S. sociology since 1945," in George Steinmetz (ed.) The Politics of Method in the Human Sciences: Positivism and Its Epistemological Others. Durham, NC: Duke University Press: 275-323. 